\title{
Infection Control and Isolation Procedures
}

\author{
Malgorzata Mikulska
}

\subsection{Introduction}

Infection control is defined as a set of measures aimed at preventing or stopping the spread of infections in healthcare settings. All HSCT recipients should follow general guidelines (e.g. CDC) for preventing healthcare-associated infections through hand hygiene, disinfection and sterilization, environmental infection control, isolation precautions and prevention of intravascular catheter-related infection (Sehulster et al. 2004; Guidelines for Hand Hygiene in Healthcare Settings (2002), Guideline for Isolation Precautions: Preventing Transmission of Infectious Agents in Healthcare Settings (2007), Guidelines for Environmental Infection Control in Health-Care Facilities (2003), all available at https://www.cdc.gov/infectioncontrol/guidelines/ index.html; Freifeld et al. 2011).

Dedicated and detailed international recommendations for HSCT recipients on preventing infectious complications have been published in 2009 (Tomblyn et al. 2009; Yokoe et al. 2009). As there were no well-executed randomized or con-

\footnotetext{
M. Mikulska ( $\bowtie)$

Division of Infectious Diseases, Department of Health Sciences (DISSAL), IRCCS Ospedale Policlinico San Martino, University of Genova, Genova, Italy

e-mail:m.mikulska@unige.it
}

trolled trials and little evidence to hand from cohort case-controlled or multiple time-series studies or uncontrolled experiments, reliance had to be placed on descriptive studies, reports of expert committees or on the opinions of respected authorities. Hence, most of these recommendations on infection control could only be graded as level III.

Isolation procedures in HSCT recipient comprise precautions universal for all healthcare settings (Standard Precautions and Transmission-Based Precautions) and those specific for HSCT and employed to prevent transmission of spores of filamentous fungi, mainly Aspergillus, with unfiltered air.

There is no consensus on specific protective environment, called also reverse isolation, for neutropenic patients. HSCT recipients should be placed in single-patient room, with adequate ventilation system (see below), if possible. However, no clear benefit of routine footwear exchange, or use of disposable gloves and gowns on the rate of infections have been demonstrated, and procedures vary significantly between institutions, with routine use of masks and disposable gloves and gowns in some but not others. On the contrary, the negative effect of strict protective isolation on patient's quality of life and well-being should be acknowledged and weighted against the evidence of benefits of single protective measures (Abad et al. 2010). 


\subsection{Standard Precautions}

Should be used universally for all patients and they include:

1. Proper hand hygiene

2. Use of standard personal protective equipment (PPE)

3. Appropriate cleaning and disinfection protocols (including those for shared equipment or toys and play areas in paediatric units)

4. Safe injection practices

5. Infection control practices for special procedures (e.g. surgical masks for lumbar puncture)

\subsubsection{Hand Hygiene}

It is by far the most effective means of prevention of pathogen transmission (Freifeld et al. 2011; Tomblyn et al. 2009). The preferred method of hand decontamination is with an alcohol-based hand rub, due to its superior convenience and reduced drying of the skin. Handwashing with soap and water is recommended if hands are visibly soiled, for example, with blood or body fluids, or after potential contact with spores of Clostridium difficile or with Norovirus. Of note, 15-30 s is the minimum necessary handwashing time.

PPE used routinely by healthcare workers during patient care and procedures are gloves, gowns (used if direct contact with patient's fluids is expected) and mouth, nose and eye protection (used during procedures which are likely to generate splashes or sprays of blood, body fluids, secretions and excretions). Routine donning of gowns upon entrance into a high-risk unit, including HSCT unit, is not indicated.

\subsection{Transmission-Based Precautions}

These are the measures used in addition to standard precautions for patients with documented or suspected infection or colonization with highly transmissible or epidemiologically important pathogens for which additional precautions are necessary to prevent transmission. The main types of transmission-based precautions are contact precautions, airborne precautions and droplet precautions. The specific PPE and the examples of pathogens which require each type of transmission-based precautions are outlined in Table 27.1.

Contact precaution should be also applied in a pre-emptive way, e.g. in case of patients transferred from high-risk facilities, pending the results of surveillance cultures. Clear criteria should be provided for appropriate discontinuation of contact precautions (usually when three different swabs from a known multidrug-resistant (MDR) positive site, taken 1-7 days apart, are negative). In case of contact precautions, and particularly if a patient is still colonized with a resistant pathogen, this information should be clearly stated on the discharge information form for the centres which will care for this patient subsequently. In case of MDR Gram-negative pathogens, full antibiotic susceptibility results should be provided to allow appropriate empirical therapy in case of severe subsequent infection.

Cough etiquette should be promoted. Additionally, transplant recipients, particularly those with respiratory symptoms, should use surgical masks and maintain special separation from others in common waiting areas, ideally a distance of at least $1 \mathrm{~m}$.

Upon entering HSCT unit, visitors should be screened for the presence of symptoms of easily transmissible diseases such as viral respiratory tract infections, gastroenteritis, etc. and, if present, advised to postpone their visit until no longer symptomatic. Also, healthcare workers with respiratory symptoms should refrain from direct patient care until the symptoms resolve. Sero negative persons who were exposed to communicable diseases such as measles or chickenpox should refrain from contact with HSCT recipients or transplant candidates until the incubation period passes without developing the disease. Instructional materials for patients and visitors on recommended hand hygiene, respiratory hygiene/cough etiquette practices and the application of transmission-based precautions should be provided. Vaccination of healthcare workers 
Table 27.1 Transmission-based precautions, to be applied in addition to standard precautions

\begin{tabular}{|c|c|c|c|}
\hline $\begin{array}{l}\text { Type of } \\
\text { precaution }\end{array}$ & $\begin{array}{l}\text { Patients placement and PPE to be used } \\
\text { by patients }\end{array}$ & $\begin{array}{l}\text { PPE for healthcare } \\
\text { personnel }\end{array}$ & Example of pathogens and comments \\
\hline Contact & $\begin{array}{l}\text { - Single room; if not available, } \\
\text { cohorting of those colonized/infected } \\
\text { by the same pathogen } \\
\text { - During transport, cover patient's } \\
\text { colonized/infected areas }\end{array}$ & $\begin{array}{l}\text { - Disposable gloves } \\
\text { and gowns } \\
\text { - Use patient- } \\
\text { dedicated or } \\
\text { disposable } \\
\text { equipment; if not } \\
\text { feasible, clean and } \\
\text { disinfect } \\
\text { thoroughly }\end{array}$ & $\begin{array}{l}\text { - Infection with Clostridium difficile } \\
\text { - Colonization or infection with MDR } \\
\text { pathogens } \\
\text { - Infectious diarrhoea due to pathogens } \\
\text { such as Salmonella, Norovirus, } \\
\text { Rotavirus, etc } \\
\text { All the units or other hospitals involved } \\
\text { in patient's care should be notified } \\
\text { about all the isolated pathogens } \\
\text { requiring contact precautions }\end{array}$ \\
\hline Droplet & $\begin{array}{l}\text { - Single room; if not available, } \\
\text { cohorting of those infected by the } \\
\text { same pathogen } \\
\text { - Surgical mask } \\
\text { - Follow CDC's respiratory hygiene/ } \\
\text { cough etiquette in healthcare setting }\end{array}$ & $\begin{array}{l}\text { - Mask (surgical) } \\
\text { - Disposable gloves } \\
\text { and gowns }\end{array}$ & $\begin{array}{l}\text { - Pathogens transmitted by respiratory } \\
\text { droplets (i.e. large-particle droplets } \\
>5 \mu \text { in size) that are generated by a } \\
\text { patient who is coughing, sneezing or } \\
\text { talking, e.g. influenza or other } \\
\text { respiratory viruses } \\
\text { In case of transplant recipients, the } \\
\text { duration of precautions should be } \\
\text { extended due to the possibility of } \\
\text { prolonged shedding caused by } \\
\text { immunodeficiency }\end{array}$ \\
\hline Airborne & $\begin{array}{l}\text { - Rooms with at least } 6 \text { (existing } \\
\text { facility) or } 12 \text { (new construction/ } \\
\text { renovation) air changes per hour and } \\
\text { direct exhaust of air to the outside (if } \\
\text { not possible, the air may be returned } \\
\text { to the air-handling system or adjacent } \\
\text { spaces if all air is directed through } \\
\text { HEPA filters) } \\
\text { - Surgical mask } \\
\text { - Follow CDC's respiratory hygiene/ } \\
\text { cough etiquette in healthcare setting }\end{array}$ & $\begin{array}{l}\text { - N95 or higher- } \\
\text { level respirator for } \\
\text { respiratory } \\
\text { protection }\end{array}$ & $\begin{array}{l}\text { - Mycobacterium tuberculosis (patients } \\
\text { with respiratory tuberculosis and } \\
\text { sputum with direct evidence of } \\
\text { mycobacteria) } \\
\text { - Measles, chickenpox and } \\
\text { disseminated herpes zoster }\end{array}$ \\
\hline
\end{tabular}

$H E P A$ high-efficiency particulate air, $M D R$ multidrug resistant, $P P E$ personal protective equipment

and household contacts is paramount and discussed in the dedicated chapter.

\subsection{Management of the Threat of MDR Bacteria}

In the era of increasing bacterial resistance, an important part of infection control deals with prevention of colonization and infection with $M D R$ bacteria (Siegel et al. 2007). Active surveillance, for example, with rectal swabs for detecting colonization with vancomycin-resistant enterococci (VRE) or carbapenem-resistant Enterobacteriaceae or nasal swabs for methicillin-resistant Staphylococcus aureus, should be performed in institutions where these pathogens are regularly encountered or in patients coming from such institutions.

The need for screening for different pathogens may vary according to local epidemiology. For instance, Italian statement on the management of carbapenem-resistant Klebsiella pneumoniae $(\mathrm{CR}-\mathrm{Kp})$ infections in HSCT was published (Girmenia et al. 2015). Briefly, they recommended active detection of CR- $K p$ carriers before and after HSCT, since the carriers have approximately $30 \%$ risk of developing CR-Kp bloodstream infection; staff education and monitoring of adherence to contact precautions; a cautious approach to declare a patient no longer colonized and a need for coordinated effort to intra- or inter-hospital transmission. HSCT is not contraindicated in MDR 
carriers, but establishing upfront the appropriate empirical therapy to be administered in case of fever during neutropenia is mandatory, and careful evaluation of the possibility of decolonization in selected cases through oral administration of nonabsorbable molecules or faecal microbiota transplantation is warranted (Girmenia et al. 2015; Bilinski et al. 2017).

In order to counteract the threat of MDR pathogens and the shortage of agents active against Gram-negative MDR bacteria, antimicrobial stewardship program should be implemented in every centre (Gyssens et al. 2013). Additionally, national systems for surveillance, with obligation for notification and recommendations for containment and infection control measures, should be put in place (Tacconelli et al. 2014).

The aim of antimicrobial stewardship is to limit the negative impact of MDR pathogens on patients' outcome, and its main elements are detailed in Table 27.2.

Successful implementation of antimicrobial stewardship is based on a multidisciplinary approach and close collaboration between the treating haematologists, microbiology laboratory and infectious diseases consultation service, including infection control unit, hospital pharmacy and hospital authorities who should recognize that this is an important step in high-quality management of infectious complications after HSCT.

Surveillance of effectiveness of infection control practices should be put in place, with regular monitoring of adherence. In case of contacttransmission pathogens, such as Clostridium difficile or MDR bacteria, laboratory data should be regularly analysed to detect any trends indicating possible increase in transmission.

\subsection{HSCT Environment}

Flowers, fountains, water leaks and waterretaining bath toys carry the risk of waterassociated infections with Gram-negative bacilli such as Pseudomonas aeruginosa or Legionella and thus should be avoided in the areas where
Table 27.2 Main elements of antimicrobial stewardship program

1. Regularly updated (e.g. every 6-12 months) surveillance of local epidemiology of infections in HSCT recipients, through reports on:

(a) Resistance rates to main antibiotics in top 10 most frequent pathogens

(b) Data on antibiotic consumption

(c) Data on patient outcomes in case of most frequent/difficult infections

2. Implementation of updated diagnostic methods and prompt reporting of microbiologic results by the laboratory in order to provide clinicians with

(a) Correct and timely diagnosis (e.g. of viral or fungal infections or Clostridium difficile, which may allow to avoid unnecessary antibiotic therapy)

(b) Rapid results of antimicrobial susceptibility testing to allow choosing the best targeted antibiotic therapy

3. Promoting appropriate antibiotic use, for example

(a) Implementing timely de-escalation or discontinuation of antibiotic treatment, particularly during neutropenia

(b) Appropriate dosing for different indications

(c) Optimized infusion strategies for time- and dose-dependent molecules, e.g. use of extended or continuous infusion of time-dependent molecules such as beta-lactams

4. Establishing and regularly updating protocols for prevention and treatment of infections, e.g. identifying antibiotic and antifungal regimens for empirical therapy in accordance with local epidemiology (e.g. prevalence of extended spectrum beta-lactamase (ESBL) producing

Enterobacteriaceae, methicillin-resistant staphylococci, azole-resistant aspergilli, etc.)

severely immunocompromised patients are being cared for (Yokoe et al. 2009). In addition, there are issues specific for HSCT recipients, such as room ventilation, intensified protective measures applied during hospital construction and renovations, avoidance of contact with soil (including potted plants) and avoidance of dust both permanently (e.g. non-carpeting and no porous surfaces) and while cleaning, all aimed at decreasing the risk of invasive aspergillosis (Yokoe et al. 2009).

CIBMTR/ASBMT/EBMT global recommendations on protective environment concerning hospital room design and ventilation are available (Yokoe et al. 2009). Briefly, allo-HSCT recipients should ideally be placed in protective 
environment rooms that incorporate several features including central or point-of-use HEPA (high-efficiency particulate air) filters with $99.97 \%$ efficiency for removing particles $\leq 0.3 \mu \mathrm{m}$ in diameter and $\geq 12$ air exchanges/ hours, with directed airflow and consistent positive air pressure differential between the patient's room and the hallway $\geq 2.5 \mathrm{~Pa}$. All these measures remove airborne fungal spores and are aimed at preventing airborne infections with filamentous fungi such as aspergilli. The efficacy of protective isolation measures in case of auto-HSCT recipients is less well established.

Currently HEPA-filtered rooms are probably available in almost all centres, while few centresfulfilled all the CIBMTR/ASBMT/EBMT requirements. However, the knowledge on the details and maintenance of protective environments in the HSCT setting was recently found inadequate, requiring education efforts and cooperation with hospital infection control and the hospital maintenance services (Styczynski et al. 2018).

During construction and renovations, due to high density of fungal spores, protective environmental measures are particularly important, and mould-control measures should be intensified and filtration efficiency should be monitored frequently to best determine appropriate time for replacement. Specific recommendations are available and should be followed (Sehulster et al. 2004). For example, construction and renovation areas should have negative air pressure relative to HSCT patient care areas to ensure that air flows from patient care areas toward construction areas, and a portable, industrial-grade HEPA filter should be used between a construction zone and the HSCT unit if a large area is under construction and negative pressure differential cannot be guaranteed. In addition, HSCT recipients may benefit from wearing N95 respirators outside HEPAfiltered areas, particularly during ongoing constructions, since unlike surgical masks, higher efficiency ones offer protection against Aspergillus spores. Active monitoring of cases of invasive mould infections should be performed in order to detect any possible outbreak.

\subsection{Food Safety in Transplant Recipients}

Drinking water should be safe; thus boiled or bottled water is to be preferred. Tap water in highly populated areas is usually regarded as safe from bacterial contamination because regularly tested for it. However, it may still contain Cryptosporidiums. Water from private wells should be avoided.

The use of low-microbial diet, which prohibits fresh fruits and vegetables and unprocessed food, did not result in a decreased incidence of infections in neutropenic patients (Sonbol et al. 2015; van Dalen et al. 2016). Standard food safety practices that emphasize safe handling and washing or thoroughly cooking food were found to be just as safe and produced no increase in infection rates or incidence of neutropenic fever. Similarly, to other immunocompromised patients, HSCT recipients should avoid foods possibly contaminated by Listeria monocytogenes, Campylobacter jejuni, Salmonella enteritidis, Toxoplasma gondii, etc. Main high-risk foods to avoid include:

- Raw or undercooked meat, poultry, fish or shellfish

- Refrigerated smoked fish

- Unpasteurized milk

- Foods with raw or undercooked eggs

- Unwashed fruits and vegetables

- Raw sprouts

- Soft cheeses made from unpasteurized milk like brie, camembert and blue-veined and fresh cheese (can be eaten if cooked)

- Hot dogs, deli meats and luncheon meats that have not been reheated to steaming hot or to $75^{\circ} \mathrm{C}$

- Unsafe water and ice made of it

Food safety practices for food handling should be followed, and specific information for cancer patients is available online (https://www.fda.gov/ downloads/Food/FoodborneIllnessContaminants/ 
UCM312793.pdf). Too restrictive diet recommendations, in the absence of the clear benefit of avoiding foods other than abovementioned, may have negative impact on patient's nutritional status and/or quality of life.

\section{Key Points}

- General guidelines for preventing healthcare-associated infections should be followed, and hand hygiene is the single most effective measure.

- Mandatory isolation procedures comprise Standard Precautions and TransmissionBased Precautions if appropriate: airborne, contact or droplets.

- Specific recommendations on ventilation, room design and protective environment during construction/renovation are provided to protect HSCT from transmission of spores of filamentous fungi, mainly Aspergillus.

- Protocols for prevention of colonization and infection with multidrug-resistant bacteria should be put in place, particularly in centres where these bacteria are already present.

- Antimicrobial stewardship program should be implemented in every centre to promote optimal use of antibiotics.

- Standard food safety practices should be applied, and only selected foods should be avoided (e.g. raw/undercook/underheated meat, fish or eggs, unpasteurized milk, unwashed fruits and vegetables, unsafe water).

\section{References}

Abad C, Fearday A, Safdar N. Adverse effects of isolation in hospitalised patients: a systematic review. J Hosp Infect. 2010;76:97-102.

Bilinski J, Grzesiowski P, Sorensen N, et al. Fecal microbiota transplantation in patients with blood disorders inhibits gut colonization with antibiotic-resistant bacteria: results of a prospective, single-center study. Clin Infect Dis. 2017;65:364-70.
Centers for Disease Control and Prevention. Guideline for hand hygiene in health-care settings: recommendations of the Healthcare Infection Control Practices Advisory Committee and the HICPAC/SHEA/APIC/ IDSA Hand Hygiene Task Force. MMWR Recomm Rep. 2002;51(RR16):1.

Freifeld AG, Bow EJ, Sepkowitz KA, et al. Clinical practice guideline for the use of antimicrobial agents in neutropenic patients with cancer: 2010 update by the Infectious Diseases Society of America. Clin Infect Dis. 2011;52:427-31.

Girmenia C, Viscoli C, Piciocchi A, et al. Management of carbapenem resistant Klebsiella pneumoniae infections in stem cell transplant recipients: an Italian multidisciplinary consensus statement. Haematologica. 2015;100:e375.

Gyssens IC, Kern WV, Livermore DM, ECIL-4, a joint venture of EBMT, EORTC, ICHS and ESGICH of ESCMID. The role of antibiotic stewardship in limiting antibacterial resistance among hematology patients. Haematologica. 2013;98:1821-5.

Sehulster LM, Chinn RYW, Arduino MJ, et al. Guidelines for environmental infection control in health-care facilities. Recommendations from CDC and the Healthcare Infection Control Practices Advisory Committee (HICPAC). Chicago: American Society for Healthcare Engineering/American Hospital Association; 2004.

Siegel JD, Rhinehart E, Jackson M, Chiarello L, Healthcare Infection Control Practices Advisory Committee. Guideline for isolation precautions: preventing transmission of infectious agents in healthcare settings. 2007. http://www.cdc.gov/ncidod/dhqp/pdf/ isolation2007.pdf.

Sonbol MG, Firwana B, Diab M, et al. The effect of a neutropenic diet on infection and mortality rates in cancer patients: a meta-analysis. Nutr Cancer. 2015;67:1230-8.

Styczynski J, Tridello G, Donnelly P, et al. Protective environment for hematopoietic cell transplant (HSCT) recipients: the Infectious Diseases Working Party EBMT analysis of global recommendations on healthcare facilities. Bone Marrow Transplant. 2018;53:1131. https://doi.org/10.1038/s41409-018-0141-5.

Tacconelli E, Cataldo MA, Dancer SJ, et al. ESCMID guidelines for the management of the infection control measures to reduce transmission of multidrug-resistant Gram-negative bacteria in hospitalized patients. Clin Microbiol Infect. 2014;20(Suppl 1):1-55.

Tomblyn M, Chiller T, Einsele H, et al. Guidelines for preventing infectious complications among hematopoietic cell transplantation recipients: a global perspective. Biol Blood Marrow Transplant. 2009;15:1143-38.

van Dalen EC, Mank A, Leclercq E, et al. Low bacterial diet versus control diet to prevent infection in cancer patients treated with chemotherapy causing episodes of neutropenia. Cochrane Database Syst Rev. 2016;4:CD006247.

Yokoe D, Casper C, Dubberke E, et al. Infection prevention and control in health-care facilities in which hematopoietic cell transplant recipients are treated. Bone Marrow Transplant. 2009;44:495-7. 
Open Access This chapter is licensed under the terms of the Creative Commons Attribution 4.0 International License (http://creativecommons.org/licenses/by/4.0/), which permits use, sharing, adaptation, distribution and reproduction in any medium or format, as long as you give appropriate credit to the original author(s) and the source, provide a link to the Creative Commons license and indicate if changes were made.

The images or other third party material in this chapter are included in the chapter's Creative Commons license, unless indicated otherwise in a credit line to the material. If material is not included in the chapter's Creative Commons license and your intended use is not permitted by statutory regulation or exceeds the permitted use, you will need to obtain permission directly from the copyright holder.

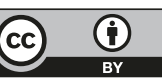

